\title{
Draft: Access Policy Guidelines
}

The following set of guidelines was prepared by the ACRL Committee on Community Use of Academic Libraries. It will be considered for approval by the ACRL Board of Directors at the 1975 Annual Conference in San Francisco. All comments and suggestions for revision should be sent to the chairman of the committee, David K. Oyler, director, Steenbock Memorial Library, College of Agricultural and Life Sciences, University of Wisconsin-Madison, Madison, WI 53706.

Members of the committee are: Jovana J. Brown, Evergreen State College; James C. Eller, Wichita State University; Darrell H. Lemke, Consortium of Universities; Mary Lou Lucy, Columbia University; Rita L. Paddock, Harvard University; Hans E. Panofsky, Northwestern University; Theodore P. Peck, University of Minnesota; and Giles B. Robertson, University of Illinois at Chicago Circle.

\section{INTRODUCTION}

The committee has developed the following guidelines to assist academic libraries, whether public or private, urban or rural, in codifying their policies with respect to access by persons other than their respective primary clientele. The guidelines are intended to deal primarily with on-site access, but they may be used as the basis to cover other means of community access such as written and telecommunications inquiries.

The goal of total access to information is a major concern of librarians as articulated by the ALA Goal and Objectives statement, the first objective of which is as follows:

Provision of library and information services and resources for all the people of the United States of America in order to increase their opportunity to participate in society, to learn, to achieve self-fulfillment, to pursue careers, and to obtain information needed for research. ${ }^{{ }^{1}}$

In addition, the National Commission on Libraries and Information Science has stated in its report, "A National Program for Library and Information Services,"

the total library and information resource in the United States is a national resource which should be developed, strengthened, organized, and made available to the maximum degree possible in the public interest. This national resource represents the cumulated and growing record of much of our nation's, and indeed, much of the world's, total cultural experi- ence-intellectual, social, technological, and spiritual."

While these two statements do not necessarily imply on-site access, or the other forms discussed, many academic libraries are mindful of the need to articulate clearly their policies relating to collections and services.

Institutional goals and circumstances are highly variable, making it both unworkable and undesirable to be prescriptive in approaching the question of community access to library collections and services. Public and private academic libraries have an obligation to examine their particular institutional goals as well as specific educational and legal responsibilities preparatory to articulating a policy on community access. The purpose of sharing library resources consistent with such a policy is to ensure that appropriate use is made of all collections and services. The reader must be assisted in terms of where to go first for material and what steps are necessary to obtain the information on material needed.

For the purposes of this document, "community" is considered to include those individuals outside the library"s primary clientele who may have occasion to make personal use of its collections and/or services.

Frequently libraries within the community have developed cooperative use agreements on the basis of the types of material collected and general, consequent strengths associated with the respective libraries. This development provides a reasonable basis for instructing a variety of users in the appropriateness of using various collections.

Whether or not formal cooperative agreements exist, librarians are obligated to be wellinformed about the policies and resources of other libraries in the area in order to make appropriate referrals. All libraries, regardless of size or prestige, have something to contribute to total information resources, and informal cooperation can help to alleviate the problems associated with community access to academic libraries.

It is recommended that the policy statement be made available to all users in an attractive format.

\section{Outline}

Consideration of the following outline may be helpful in arriving at and stating an access policy.
1.0 PURPOSE OF LIBRARY
2.0 COLLEGE OR UNIVERSITY LIBRARY CHARACTERISTICS 
2.1 Location of library-urban, rural.

2.2 Source of library funding-public, private.

2.3 Strength of library collections.

2.4 Number of persons constituting primary clientele.

$2.5 \mathrm{Space} /$ seats available for users.

2.6 Service personnel available by function, location, day and time.

2.7 Administrative services-where policy inquiries are to be directed.

2.8 Legal obligations and restrictions.

3.0 COMMUNITY FACTORS

3.1 Other libraries in the community.

3.1.1 Location.

3.1.2 Size.

3.1.3 Nature of collections.

3.1.4 Services.

3.1.5 Clientele.

3.1.6 Regulations for use.

3.1.7 Networking and cooperative arrangements.

3.2 Social and political factors.

4.0 CHARACTERISTICS OF POTENTIAL USERS

4.1 Size of groups.

4.2 Age and educational level.

4.3 Nature and purpose of use.

4.4 Types of material to be used.

4.5 Hours of use.

4.6 Services required.

4.6.1 Informational and directional assistance.

4.6.2 Reference assistance.

4.6.3 Borrowing: registration, notices, billing, etc.

4.6.4 AV systems and equipment use.

4.6.5 Copying service.

4.6.6 Use of meeting space, display space.

4.6.7 Interlibrary loan.

4.6.8 Special fee-based services.

Note: Specific institutional policy statements should incorporate relevant factors from the foregoing outline. It is not intended that the outline itself prescribe the form and character of the resulting policy statement.

\section{Sample Outrine for a Policy Statement}

1 Definition of library purpose.

Statements of mission and goals immediately establish the basis for public expectations. For example, if non-academic users and those otherwise not immediately associated with the particular institution are told they do not constitute part of the primary clientele, they have modified expectations. This statement ought to be presented in positive language, briefly stating the nature of the library mission.

An example of such language follows:

The library constitutes a vital in- structional and research arm of the University of $\_$and exists primarily to contribute to the university's teaching and research functions. In addition, the library seeks to serve the citizens of the State of - consistent with its primary function and within the limits of its resources.

If liberal access and service are the norm, this can be reflected in the mission statement. A statement of how the library fits into a general plan of library services among libraries in the state or other organized service groups might also be included, if available.

2 Basis for community service.

2.1 Definition of community.

2.2 Categories of eligible users.

3 Specification of identification and types of access.

3.1 I.D. cards, or introductory letters from home institutions, consortia cards, or cooperative library cards, etc., required.

3.2 Non-fee access.

3.3 Fee access.

3.3.1 Identification of fee categories and amounts.

3.3.2 Basis of valid fee period (i.e., semester, quarter, fiscal or calendar year, etc.).

3.3.3 Payment details (when and where).

4 Services.

4.1 Circulation regulations.

4.1.1 Identification required of user.

4.1.2 Loan periods if applicable (specify general-use materials not subject to loan and loan periods by type if applicable).

4.1.3 Access to special collections or library branches if not covered above.

4.1.4 Special distinctions among non-campus users if applicable (e.g., students from other colleges, schools, teachers, other professionals ).

4.1.5 Sanctions (including fines and replacement of lost or damaged material).

4.2 Security measures-exit control.

4.3 Information services.

4.3.1 Description of available services by broad subject or type (e.g., humanities, documents, archives, maps, etc.) and location.

4.3.2 Basis of access (in-person, phone, letter, etc.).

4.3.3 Hours of service (noting special limitations for community users).

4.4 Other services.

4.4.1 Reproduction services and costs.

4.4.2 AV equipment and personnel available.

4.4.3 Conference rooms/auditoriums (availability and process for reserving). 
4.4.4 Display space.

4.4.5 Special fee-based services (e.g., access to computerized bibliographic data bases).

\section{REFERENCES}

1. Goal and Objectives of the American Library Association, as adopted by the Council of the American Library Association. January $24,1975$.

2. "A National Program for Library and Information Services." 2d Draft (Rev.) Prepared by the National Commission on Libraries and Information Science. September 15, 1974. Washington, D.C.

\section{Guidelines}

Continued from page 139

have will request that they be borrowed from another library.

T4. The student can make effective use of the library resources available to him.

a. He knows how to use institutional holdings records (such as the card catalog and serials holdings lists) to locate materials in the library system.

E1. Given a map of the library, the student can correctly identify the location of the library's catalog (e.g., card catalog, book catalog, public shelf list) and other holdings lists in $3^{*}$ minutes.

E2. The student will correctly identify and explain the purpose of selected elements on a sample cata$\log$ entry in $5^{\circ}$ minutes. The selected elements will include: the author, title, place of publication, publisher, date of publication, series title, bibliographic notes, tracings, and call number.

E3. Given a topic or list of topics, the student will accurately list the items found in the catalog on those topics in a specified period of time. The topics will include items which require the student to use the U.S. Library of Congress Subject Headings Used in the Dictionary Catalog of the Library of Congress. The student will also have to demonstrate his knowledge of form subdivisions, and subject filing rules such as

* An asterisk beside an item indicates that the task force does not recommend it; it is only suggestive. historical subdivisions are filed in chronological order.

E4. Given a list of materials, the student, in a specified time, can correctly identify and locate those materials which the library owns. The list shall include incomplete citations, citations which are listed under entries other than the "main entry." It will also include:

Book (individual author)

Book (corporate or institutional author)

Journal (recent issue)

Journal (older or discontinued title)

Newspaper

U.S. Document

Pamphlet

Non-book materials

Microform

Other, as appropriate to the institution

This list will include items which require the student to demonstrate his knowledge of selected filing rules such as: initial articles are ignored in filing, abbreviations are filed as if spelled out, $\mathrm{Mc}$ is filed as if spelled Mac, numerals are filed as if spelled out.

b. He knows how to use reference tools basic to all subject areas.

E1. Given a map of the library, the student can correctly identify the location of the reference department (and its catalog) in a specified time period.

E2. In a specified time period, the student can identify major reference tools (encyclopedia, dictionary, index) in an unfamiliar field using a guide to the literature such as Winchell's Guide to Reference Books.

E3. In a specified time period, the student can list five periodical titles (and the indexes which cover them) in an unfamiliar subject field using a directory such as Ulrich's International Periodical Directory.

E4. In a specified time period, the student will list five titles available on an unfamiliar topic using a bibliography such as Subject Guide to Books in Print, Bibliographic Index, Library of Congress, Books: Subjects.

E5. Given a topic with which the student is unfamiliar, in a specified time period, he will locate a gen- 